\title{
The Complexed Triphosphaallyl Radical, Cation, and Anion Family**
}

\author{
Manfred Scheer,* Christian Kuntz, Markus Stubenhofer, Michael Linseis, Rainer F. Winter, and \\ Marek Sierka
}

\author{
Dedicated to Professor Joachim Sauer on the occasion of his 60th birthday
}

The allyl radical $\mathbf{A}$ is of fundamental importance in both experimental and theoretical organic chemistry. ${ }^{[4]}$ Structures of allyl radical compounds stabilized by bulky substituents have been reported by the research groups of Streitwieser ${ }^{[3]}$ and Azuma. ${ }^{[4]}$ Moreover, the allyl anion and the amidinato ligand $\mathbf{B}$, the latter formed by the replacement of $\mathrm{CR}_{2}$ by isolobal NR moieties, are prominent ligands in coordination chemistry. Amidinate ligands B, which have bulky substitu ents on the $\mathrm{N}$ atoms, have been used to stabilize molecules in unusual bonding situations. ${ }^{\left[{ }^{10]}\right.}$ The replacement of $\mathrm{CR}^{\prime}$ in the allyl radical $\mathbf{A}$ by isolobal phosphorus gives a 2 phosphaallyl radical $\mathbf{C}$. Compounds of type $\mathbf{C}$ have only been synthesized in situ by electrochemical reduction of 2 phosphaallyl cat ions, ${ }^{[1]}$ and their structural parameters have been calculated by using quantum chemical methods. ${ }^{[12]}$ The stability of such systems can be increased by embedding the radical in a four membered 1,3 diphosphacyclobutenyl ring system. ${ }^{[13,14]}$ The replacement of the terminal $\mathrm{CR}_{2}$ groups by isolobal $\mathrm{PR}^{\prime}$ fragments in $\mathbf{A}$ to yield the 1,3 diphosphaallyl radical $\mathbf{D},{ }^{[15]}$ as well as its cationic derivative $\mathbf{D}^{\prime}\left(\mathrm{R}^{\prime}=\mathrm{NR}_{2}\right),{ }^{[16]}$ were reported by Bertrand and co workers. However, no crystallographic proof for the structures of these compounds has been reported to date. Complete isolobal replacement of the $\mathrm{CR}$ units in the allyl radical $\mathbf{A}$ by $\mathbf{P}$ leads to the triphosphaallyl radical $\mathbf{E}$, which is also unreported to date. Herein, we report a straightforward synthesis of an air stable complexed tri phosphaallyl radical $\mathbf{E}$ by photolysis of the $\mathrm{Cp}$ * containing $\left(\mathrm{Cp} *=\mathrm{C}_{5} \mathrm{Me}_{5}\right)$ phosphinidene complex with a diphosphene and its transformation into its anionic $(\mathbb{F})$ and cationic $\left(\mathbf{F}^{\prime}\right)$ derivatives. ${ }^{[17]}$ Interestingly, Jutzi et al. have reported spec

[*] Prof. Dr. M. Scheer, Dr. C. Kuntz, M. Stubenhofer, M. Linseis, Prof. Dr. R. F. Winter

Institut für Anorganische Chemie der Universität Regensburg 93040 Regensburg (Germany)

Fax: (+49) 9419434441

E mail: manfred.scheer@chemie.uni regensburg.de

Dr. M. Sierka

Institut für Chemie der Humboldt Universität zu Berlin Unter den Linden 6, 10099 Berlin (Germany)

[**] This work was supported by the Deutsche Forschungsgemeinschaft and the Fonds der Chemischen Industrie. M.S. gratefully acknowl edges Prof. Joachim Sauer and the Humboldt Universität zu Berlin for providing computing facilities.

D) Supporting information for this article (full synthetic and spectro scopic details for $\mathbf{2} \mathbf{5}$, and full details and references for the DFT calculations and the spectroelectrochemical investigations) is available on the WWWW under http://dx.doi.org/10.1002/anie. 200805892. troscopic evidence for the anion $\mathbf{F}$ and its 2 arsa conge ner. ${ }^{[18]}$

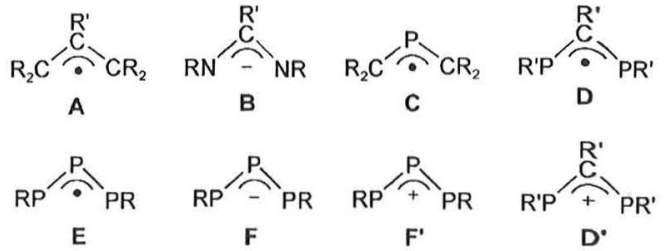

We have shown that the phosphinidene complex $\left[\mathrm{Cp} * \mathrm{P}\left\{\mathrm{W}(\mathrm{CO})_{5}\right\}_{2}\right](\mathbf{1})^{[19]}$ is an excellent starting material for the in situ generation of intermediate $\mathbf{G},{ }^{[20]}$ which contains a tungsten phosphorus triple bond (Scheme 1). The intermedi

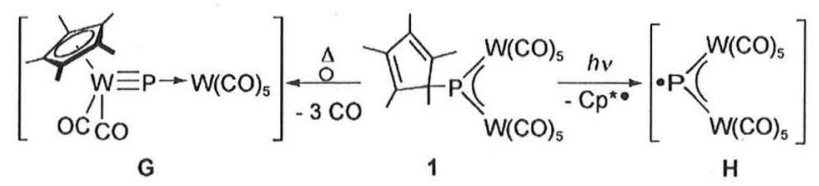

Scheme 1. Different transformation pathways in the photolysis and thermolysis of $\mathbf{1}$.

ate can be trapped by organometallic compounds that contain multiple metal metal bonds, ${ }^{[21]}$ alkynes, ${ }^{[22]}$ and phosphaal kynes to give novel clusters, metal containing heterocycles, or cage compounds. In the latter reaction, an unusual opening of the $\mathrm{Cp}^{*}$ ligand is observed to form an unprecedented 1,2 diphosphacyclooctatetraene ligand. ${ }^{[23]}$ Compound $\mathbf{G}$ is formed by $\mathrm{Cp}^{*}$ migration from phosphorus to tungsten with a change in the coordination mode from $\eta^{1}$ to $\eta^{5}$ (Scheme 1). This reaction proceeds primarily under thermolytic condi tions, however, photolysis of $\mathbf{1}$ leads, additionally, to the elimination of a $\mathrm{Cp}^{* \bullet}$ moiety and the formation of the radical intermediate $\mathbf{H}^{\left[{ }^{[2]]}\right.}$ The electronic structure of $\mathbf{H}$ was recently calculated by using DFT methods. ${ }^{[21]}$ We now find that this intermediate acts as a phosphorus radical transfer reagent and is responsible for the reaction of $\mathbf{1}$ with diphosphenes to afford an unprecedented complex of type $\mathbf{E}$.

Photolysis of 1 in the presence of Mes*P $=$ PMes* $^{*}$ (Mes* $=$ $2,4,6$ tri tert butylphenyl) in toluene at $15^{\circ} \mathrm{C}$ results in a color change from deep blue to greenish brown over a period of five hours, which indicated the completion of the reaction (Scheme 2). Separation of the crude reaction mixture by preparative TLC resulted in the isolation of a blackish green 
<smiles>CC1=C(C)C(C)(P([N+](=O)[O-])[N+](=O)[O-])C(C)=C1C</smiles>

1

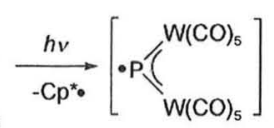

$\mathrm{H}$

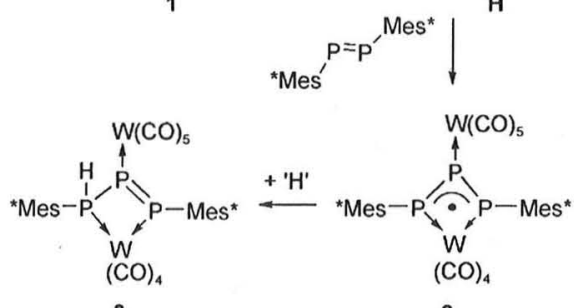

Scheme 2. Synthesis of the complexed triphosphaallyl radical

fraction, from which the radical species 2 was obtained as a black crystalline compound in $22 \%$ yield. Compound $\mathbf{3}$ was isolated from the second, blue fraction as a dark green crystalline compound in $35 \%$ yield. The ${ }^{31} \mathrm{P}$ NMR spectrum of the reaction mixture shows no signals that correspond to $\mathbf{3}$, thus it seems that $\mathbf{3}$ was formed during the chromatography as a decomposition product of 2 . When the TLC plates were dried, hydrogen abstraction was prevented and the yield of isolated 2 increased to $40 \%$, with only traces of $\mathbf{3}$ being produced. Since no thermal reaction between the starting materials occurs, the nucleophilic attack of the diphosphene at the electrophilic phosphinidene phosphorus atom can be excluded. Complex $\mathbf{2}$ is thus likely to be formed by addition of the photogenerated radical $\mathbf{H}$ to the $\mathrm{P}=\mathrm{P}$ bond of the diphosphene, followed by a rearrangement.

Compounds $\mathbf{2}$ and $\mathbf{3}$ are readily soluble in hexane and $\mathrm{CH}_{2} \mathrm{Cl}_{2}$, and give the expected IR spectroscopic and mass spectrometric data. The ${ }^{31} \mathrm{P}\left\{{ }^{1} \mathrm{H}\right\}$ NMR spectrum of $\mathbf{3}$ shows three doublets of doublets of an AMX spin system, each of which with a pair of tungsten satellites. The signal for the hydrogen bearing $\mathrm{P}$ atom is shifted upfield $(\delta=-62.4 \mathrm{ppm})$ from the $\mathrm{P}$ atoms of the $\mathrm{P}=\mathrm{P}$ bond $(\delta=382.4$ and $450.6 \mathrm{ppm}$, $\left.{ }^{1} J(\mathrm{P}, \mathrm{P})=271 \mathrm{~Hz}\right)$. Interestingly, all three signals in the ${ }^{31} \mathrm{P}$ NMR spectrum of $\mathbf{3}$ show an eight line pattern, which is attributed to the $\mathrm{PH}$ couplings. ${ }^{[25]}$ No NMR signal is observed for radical 2 because of the paramagnetic line broadening. The EPR spectrum of a solution of $\mathbf{2}$ in hexane at room temperature shows a six line signal that can be interpreted as doublets of a triplet at a $g$ value of 2.0176 . The ${ }^{31} \mathrm{P}$ hyperfine coupling constants are determined as $8.91 \mathrm{mT}$ (terminal $\mathrm{P}$ atoms) and $2.11 \mathrm{mT}$ (central $\mathrm{P}$ atom). ${ }^{[25]}$ Interestingly, the coupling constants derived for $\mathbf{2}$ are larger than the experimental values for the proposed derivative $D ;^{[15]}$ although, according to the calculations, the spin density in $\mathbf{D}$ should be located at the terminal $\mathbf{P}$ atoms, as in $\mathbf{2}$.

The electrochemical behavior of 2 was studied by cyclic voltammetry. ${ }^{[25]}$ The voltammogram of $\mathbf{2}$ exhibits a reversible one electron oxidation to the corresponding cation at $0.17 \mathrm{~V}$, and a reversible one electron reduction to the corresponding anion at $-0.81 \mathrm{~V}$. Spectroelectrochemical investigations show that the reduction of $\mathbf{2}$ leads to a shift of the carbonyl bands to lower wavenumbers. The values of the electrochemical potentials of 2 imply that $\mathrm{AgSbF}_{6}$ and $\left[\mathrm{CoCp}_{2}\right]$, respectively, are suitable reagents for the oxidation and reduction of 2. ${ }^{[26]}$ The reaction of 2 with one equivalent of $\mathrm{AgSbF}_{6}$ in $\mathrm{CH}_{2} \mathrm{Cl}_{2}$ $\left(E^{0}=+0.65 \mathrm{~V}^{[26]}\right)$ at $-78^{\circ} \mathrm{C}$ led to the oxidation product 4 (Scheme 3 ). This reaction was accompanied by a rapid color

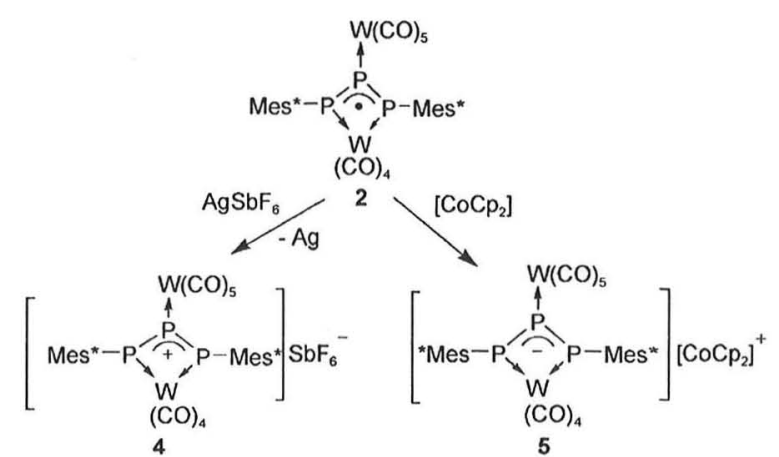

Scheme 3. Oxidation and reduction of the complexed triphosphaallyl radical.

change from blackish green to deep purple and the appear ance of a silver mirror. The ${ }^{31} \mathrm{P}$ NMR spectrum of the purple solution shows a $\mathrm{AM}_{2}$ spin system with signals at $\delta=$ $586.5 \mathrm{ppm} \quad\left({ }^{1} J(\mathrm{P}, \mathrm{P})=250 \mathrm{~Hz},{ }^{1} J(\mathrm{P}, \mathrm{W})=272 \mathrm{~Hz}\right)$ and $\delta=$ $344.5 \mathrm{ppm}\left({ }^{1} J(\mathrm{P}, \mathrm{P})=250 \mathrm{~Hz},{ }^{1} J(\mathrm{P}, \mathrm{W})=267 \mathrm{~Hz}\right)$, thus indicat ing the formation of a cation in which the two terminal $\mathrm{P}$ atoms of the $\mathrm{P}_{3}$ unit are symmetry equivalent. The ESI mass spectrum of the reaction mixture of $\mathbf{4}$ shows the $\mathrm{SbF}_{6}{ }^{-}$ion at $\mathrm{m} / \mathrm{z} 235$ and the molecular ion peak of the cation at $\mathrm{m} / \mathrm{z} 1203$ We were not able to isolate 4 from the reaction mixture because of its rapid decomposition (within 30 minutes) at room temperature.

Treatment of 2 with stoichiometric amounts of $\left[\mathrm{CoCp}_{2}\right]$ in $\mathrm{CH}_{2} \mathrm{Cl}_{2}\left(E^{0}=-1.33 \mathrm{~V}^{[26]}\right)$ at $-78^{\circ} \mathrm{C}$ resulted in the formation of the diamagnetic reduction product $\mathbf{5}$ (Scheme 3 ) as a green compound, which was isolated in $57 \%$ yield. All the signals in the $\mathrm{A}_{2} \mathrm{M}$ type ${ }^{31} \mathrm{P}\left\{{ }^{1} \mathrm{H}\right\}$ NMR spectrum of $\mathbf{5}$ are shifted upfield compared to those of $4\left(\mathrm{P}_{\mathrm{A}}\right.$ atom $4: \delta=586.5 \mathrm{ppm}, \mathbf{5}: \delta=$ $468.5 \mathrm{ppm} ; \mathrm{P}_{\mathrm{M}}$ atom 4: $\left.\delta=344.5 \mathrm{ppm}, 5: \delta=108.3 \mathrm{ppm}\right)$. The ${ }^{1} J(\mathrm{P}, \mathrm{P})$ coupling constant increases from $250 \mathrm{~Hz}$ in 4 to $378 \mathrm{~Hz}$ in 5 , which reveal ${ }^{1} J(\mathrm{P}, \mathrm{W})$ couplings of $207 \mathrm{~Hz}$ and $157 \mathrm{~Hz}$, respectively. ${ }^{[25]}$ The IR absorptions for the CO ligands of 5 agree with those obtained upon reduction of 2 at $-0.90 \mathrm{~V}$ under the in situ spectroelectrochemistry conditions. ${ }^{[25]}$ The large shifts of the $\left\{\mathrm{W}(\mathrm{CO})_{4}\right\}$ bands compared to those of the $\left\{\mathrm{W}(\mathrm{CO})_{5}\right\}$ moiety suggest that the terminal P1 units are more affected by reduction than the central atom $\mathrm{P} 2$.

Single crystals of 2 were obtained at $-25^{\circ} \mathrm{C}$ from its $\mathrm{CH}_{2} \mathrm{Cl}_{2}$ solution. In its crystalline state, radical 2 surprisingly showed no apparent decomposition, even in air at room temperature for several days. The molecular structure of $2^{[27]}$ is shown in Figure 1 and reveals a Mes* substituted phos phaallylic system, which is $\eta^{2}$ coordinated to a $\left\{\mathrm{W}(\mathrm{CO})_{4}\right\}$ unit by the phosphorus atoms $\mathrm{P} 1$ and $\mathrm{P}^{\prime}$. The central atom of the three membered phosphorus chain $\mathrm{P} 2$ is $\eta^{1}$ coordinated to a $\left\{\mathrm{W}(\mathrm{CO})_{s}\right\}$ unit. The molecule has $C_{2}$ symmetry with the central unit, which consists of the seven atoms C6, C6', P1, P1', $\mathrm{P} 2$, W1, and W2, situated within one plane. The P1/P1'-P2 


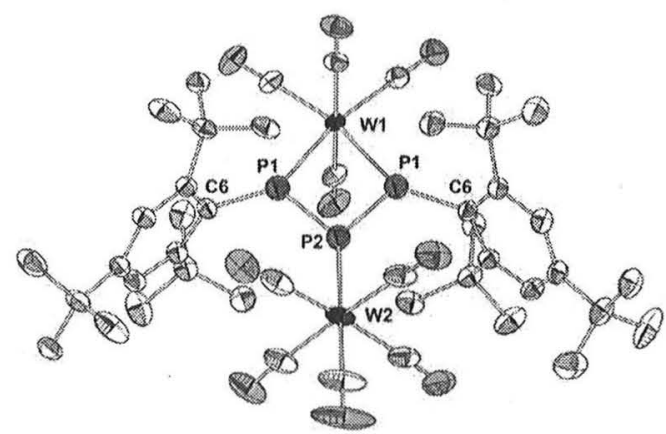

Figure 1. ORTEP representation of $\mathbf{2}$ (hydrogen atoms omitted for clarity, thermal ellipsoids set at $50 \%$ probability).

bond length $(2.112(2) \AA)$ is the average of a P-P bond $\left(\beta \mathrm{P}_{4}\right.$ : $2.20 \AA^{[28]}$ ) and a $\mathrm{P}=\mathrm{P}$ bond (the calculated bond length for $\mathrm{H}^{-}$ $\mathrm{P}=\mathrm{P}-\mathrm{H}$ is $\left.2.004 \AA^{[29]}\right)$. These data suggest a bond order of 1.5 , which is commonly found in allylic systems. The P1 P2 P1' angle $\left(83.7(1)^{\circ}\right)$ is diminished compared to that of an organic allylic system. The Mes* groups are twisted against the P1 P1' P2 W1 W2 plane with a dihedral angle of $85.7(1)^{\circ}$, which prevents conjugation between the $\mathrm{W}_{2} \mathrm{P}_{3}$ system and the phenyl rings.

The molecular structure of 3 (Figure 2) ${ }^{[27]}$ reveals that protonation of 2 at the P1 atom distorts the coplanar arrangement of the $\mathrm{P}$ and $\mathrm{W}$ atoms. The $\mathrm{P} 1-\mathrm{P} 2$ bond length (2.187(3) $\AA$ ) corresponds to a single bond, whereas the P2-P3 bond $(2.075(3) \AA$ ) corresponds to a double bond.

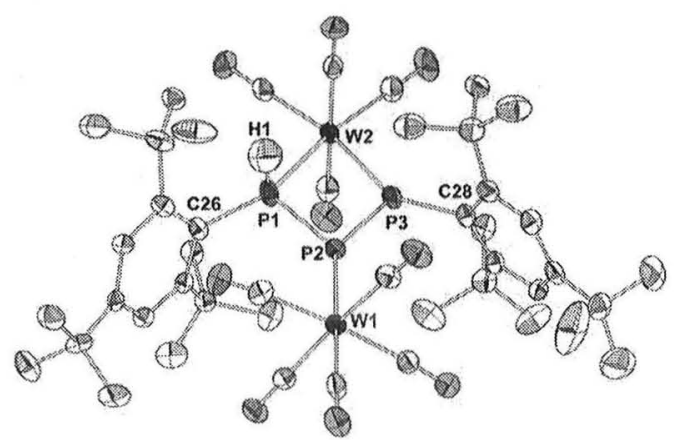

Figure 2. ORTEP representation of 3 (hydrogen atoms omitted for clarity, thermal ellipsoids set at $30 \%$ probability).

The cobaltocenium salt 5 crystallized from a $\mathrm{CH}_{2} \mathrm{Cl}_{2}$ solution. The experimental $\mathrm{X}$ ray structure of $\mathbf{5}$ (Figure 3 ) $^{[27]}$ differs only slightly from the $C_{2}$ symmetric one (see DFT calculations). Deviations from ideal symmetry are probably due to packing effects in the presence of the counterion in the crystal lattice. The same behavior is also found for 2. $\mathrm{CH}_{2} \mathrm{Cl}_{2}{ }^{[25,27]}$ In contrast to the radical 2, the $\mathrm{P}-\mathrm{P}$ bond lengths are shortened (P1-P2 2.070(3) $\AA$, P2-P3 2.065(3) $\AA$ ) in the anion of 5 , whereas the $\mathrm{W}-\mathrm{P}$ bond lengths are elongated (W1-P1 2.568(2) $\AA$, W1-P3 2.552(2) $\AA$, W2-P2 $2.492(2) \AA)$. Additionally, the coplanar arrangement of the atoms C6, C6', P1, P1', P2, W1, and W2 atoms in 2 is distorted.

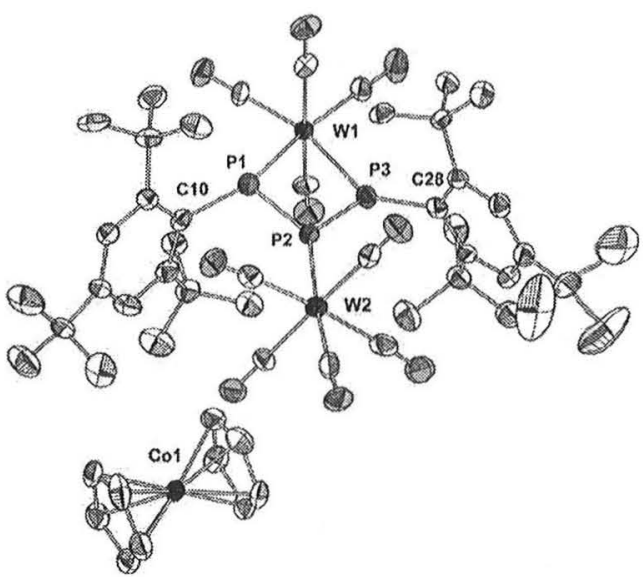

Figure 3. ORTEP representation of $\mathbf{5}$ (hydrogen atoms omitted for clarity, thermal ellipsoids set at $50 \%$ probability).

DFT calculations showed the energy minima for 2,4 , and 5 to be $C_{2}$ symmetric, which are lower in energy than their $C_{2 v}$ symmetric counterparts by $4.1,4.5$, and $16.3 \mathrm{~kJ} \mathrm{~mol}^{-1}$, respec tively. Selected calculated and experimental structure para meters of the central W2 $\left(\eta^{1}\right) \mathrm{P}_{3}\left(\eta^{2}\right)$ W1 unit in $\mathbf{2 , 4}$, and $\mathbf{5}$ are given in Table 1. The agreement between predicted and

Table 1: Comparison of selected theoretical and experimental structural parameters $\left[\AA{ }^{\circ},{ }^{\circ}\right]$ of 4,2 , and 5 .

\begin{tabular}{llllll}
\hline Parameter & 4 & \multicolumn{2}{c}{2} & \multicolumn{2}{c}{$\mathbf{5}^{[a]}$} \\
& Calcd & Calcd & Exp & Calcd & Exp \\
\hline P1 W1 (P1' W1) & 2.468 & 2.531 & $2.468(1)$ & 2.615 & $2.568(2.552)$ \\
P2 W2 & 2.472 & 2.535 & $2.471(2)$ & 2.590 & 2.492 \\
P1 P2 (P1' P2) & 2.159 & 2.134 & $2.112(2)$ & 2.110 & $2.070(2.065)$ \\
P1 C6 (P1' C6') & 1.831 & 1.844 & $1.835(3)$ & 1.870 & $1.855(1.833)$ \\
P1 P2 P1' & 81.9 & 84.6 & $83.7(1)$ & 88.99 & $88.70(10)$ \\
P1 P2 P1' C6 & 180.0 & 180.0 & 180.0 & 156.7 & $156.4(2)^{[b]}$ \\
\hline
\end{tabular}

[a] The atoms $\mathrm{Pl}^{\prime}, \mathrm{C} 6$, and $\mathrm{C}^{\prime}$ in 5 correspond to $\mathrm{P} 3, \mathrm{C} 28$, and $\mathrm{C} 10$, respectively, in Figure 3. [b] Value for the P3 P2 P1 C10 angle; the P1 P2 P3 C28 angle is $160.3(2)^{\circ}$ (see Figure 3 ).

experimental values is good for the radical $\mathbf{2}$ and anion $\mathbf{5}$, except for slightly overestimated $\mathrm{P}-\mathrm{W}$ bond lengths. As a general trend, the increasing number of electrons in 4,2 , and 5 causes significant elongation of the $\mathrm{P}-\mathrm{W}$ bond (the calculated difference between $\mathbf{4}$ and $\mathbf{5}$ is ca. $0.15 \AA$ ) and a slight contraction of the $\mathrm{P}-\mathrm{P}$ bond lengths. The central ditungsten triphosphaallyl moiety in $\mathbf{2}$ and $\mathbf{4}$ remains coplanar with the C6/6' atoms and the difference between the $C_{2}$ and $C_{2 v}$ symmetric structures is merely a rotation of two para tert butyl groups of the Mes* substituents. Both $\mathrm{P}-\mathrm{C}$ bonds in $\mathbf{5}$ are tilted about $23^{\circ}$ from the plane of the W2 $\left(\eta^{1}\right) \mathrm{P}_{3}\left(\eta^{2}\right) \mathrm{W} 1$ unit.

The molecular orbital analysis of the central W2 $\left(\eta^{1}\right) \mathrm{P}_{3}\left(\eta^{2}\right)$ W1 moiety in $\mathbf{2}, \mathbf{4}$, and $\mathbf{5}$ gives some insight into their bonding. The isosurface orbital plots of the $\pi$ orbital system in the ditungsten triphosphaallyl unit of all three compounds is shown in Figure 4. In $\mathbf{2}$ and $\mathbf{4}$, the orbitals $3 \mathrm{~b}$, 4a, 

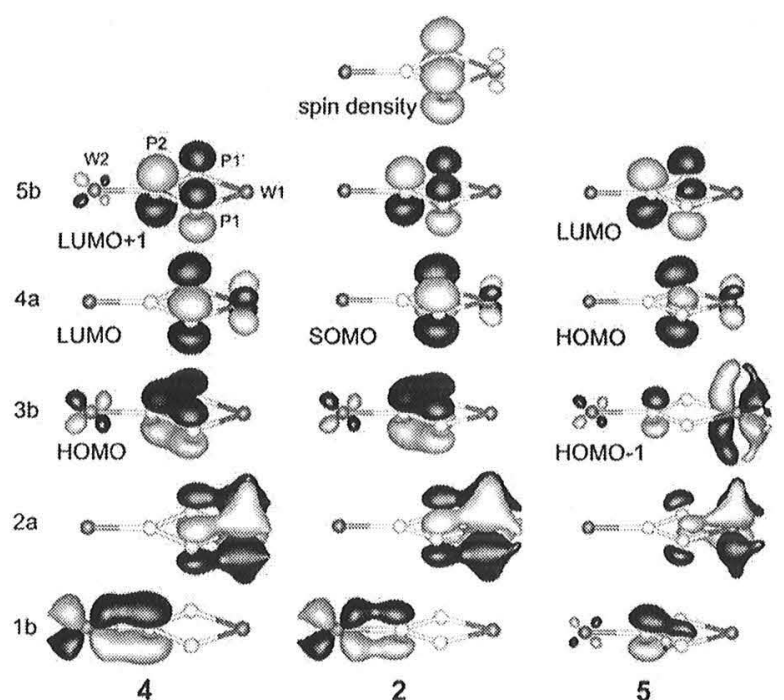

Figure 4. Isosurface orbital plots of the $\pi$ system in the ditungsten triphosphaallyl unit in cation 4, radical 2 (natural orbitals and spin density), and anion $\mathbf{5}$. The orbitals are labeled by their numerical order and symmetry.

and 5 b closely resemble the classical $\pi$ system of the $C_{3}$ allyl anion, radical, and cation, respectively. The shape of the 4a orbital in 2 and the corresponding spin density explains the high spin densities at the terminal $\mathrm{P}$ atoms and agrees with the experimental EPR data. Additionally, the orbital picture also reveals a resonance stabilization of the central $\mathrm{P}_{3}$ allyl moiety by an admixture of $\mathrm{d}$ orbitals of both $\mathrm{W}$ atoms. The $1 \mathrm{~b}$ orbital shown in Figure 4 is a $\mathrm{p}(\mathrm{P} 2) d(\mathrm{~W} 2) \pi$ bonding combination in 4 and 2 . In all three compounds, the $2 \mathrm{a}$ and $4 \mathrm{a}$ orbitals are bonding and antibonding combinations, respectively, of the $\mathrm{p}\left(\mathrm{P} 1 / 1^{\prime}\right)$ and $\mathrm{d}(\mathrm{W} 1)$ orbitals. The increasing occupation of the 4a antibonding $\mathrm{p}\left(\mathrm{P} 1 / 1^{\prime}\right) \mathrm{d}(\mathrm{W} 1)$ orbital from cation 4 to anion 5 results in a destabilization of the $\mathrm{p}(\mathrm{P}) \mathrm{d}(\mathrm{W})$ orbital system and elongation of the $\mathrm{P}-\mathrm{W}$ bonds. As a result of full occupation of the $4 \mathrm{a}$ antibonding orbital, the orbital compo sition of anion $\mathbf{5}$ is different to those of $\mathbf{4}$ and $\mathbf{2}$. The highest occupied molecular orbital (HOMO) of $\mathbf{5}$ is a doubly occupied antibonding $\mathrm{p}\left(\mathrm{P} 1 / 1^{\prime}\right) \mathrm{d}(\mathrm{W} 1)$ orbital and HOMO-1 is a nonbonding combination of $\mathrm{p}(\mathrm{P} 2)$ and $\mathrm{d}(\mathrm{W} 1 / 2)$ orbitals. The $\pi$ bonding combination of $\mathrm{p}$ orbitals of the $\mathrm{P}_{3}$ group shifts significantly $(2.2 \mathrm{eV})$ below the HOMO level (1b in Figure 4, see Ref. [25] for orbital energies), which explains the increased $\mathrm{P}-\mathrm{P}$ bond strength and the shortening of the $\mathrm{P}-\mathrm{P}$ bond distances along the series from the radical 2 to the anion $\mathbf{5}$.

In summary, we have shown that the photolytic reaction of 1 with a diphosphene yields an unprecedented air stable triphosphaallyl radical $\left[(\mathrm{CO})_{5} \mathrm{~W}\left(\mu, \eta^{2}: \eta^{1} \mathrm{P}_{3} \mathrm{Mes}_{2}\right) \mathrm{W}(\mathrm{CO})_{4}\right]$ (2). Oxidation of 2 leads to the triphosphaallyl cation (in compound 4), which is only stable at low temperatures in solution, whereas upon reduction the stable triphosphaallyl anion (in compound 5) is formed. Compounds 2, 4, and 5 represent the so far elusive redox congeners of the triphos phaallyl system. The frontier orbitals are indicative of a $\pi$ allylic system that is partially resonance stabilized by the d orbitals of both W atoms. The singly occupied molecular orbital (SOMO) and the corresponding spin density distribu tion of the radical 2 show that the unpaired spin is evenly distributed over both terminal P atoms; this is confirmed by EPR spectroscopy. The photogenerated phosphinidene rad ical $\mathbf{H}$ has been shown to be an excellent phosphorus radical transfer reagent and is thus valuable for future investigations into the generation of different open shell systems.

Received: December 3, 2008

Published online: February 26, 2009

ywords: allyl ligands . DFT calculations - phosphinidines . phosphorus - radicals

[1] M. J. Plater, S. Kemp, E. Lattmann, J. Chem. Soc., Perkin Trans. $12000,971979$.

[2] B. Giese, W. Damm, R. Batra, Chemtracts: Org. Chem. 1994, 7, 355370 .

[3] S. G. DiMagno, K. C. Waterman, D. V. Speer, A. Streitwieser, $J$. Am. Chem. Soc. 1991, 113, 46794681.

[4] N. Azuma, T. Ozawa, J. Yamauchi, Bull. Chem. Soc. Jpn. 1994, 67,3138

[5] F. T. Edelmann, Coord. Chem. Rev. 1994, 137, 403 481, and references therein.

[6] J. Barker, M. Kilner, Coord. Chem. Rev. 1994, 133, 219 300, and references therein.

[7] E. A. C. Brussee, A. Meetsma, B. Hessen, J. H. Teuben, Organo metalics 1998, 17, 40904095.

[8] a) M. P. Coles, Dalton Trans. 2006, 985 1001; b) P. J. Stewart, A. J. Blake, P. J. Mountford, Inorg. Chem. 1997, 36, 19821986.

[9] a) N. Thirupathi, G. P. A. Yap, D. S. Richeson, Organometallics 2000, 19, 2573 2579; b) K. Albahily, E. Koc, D. Al Baldawi, D. Savard, S. Gambarotta, T. J. Burchell, R. Duchateau, Angew. Chem. 2008, 120, 5900 5903; Angew. Chem. Int. Ed. 2008, 47, $58165819 ;$ c) S. P. Green, C. Jones, A. Stasch, Science 2007, 318 , 17541757.

[10] S. Nagendran, H. W. Roesky, Organometalics 2008, 27, 457 492.

[11] a) A. Schmidpeter, S. Lochschmidt, A. Willhalm, Angew. Chem. 1983, 95, 561 562; Angew. Chem. Int. Ed. Engl. 1983, 22, 545 546; b) A. Schmidpeter, A. Willhalm, J. Kroner, R. O. Day, J. M. Holmes, R. Holmes, Phosphorus Sulfur 1987, 30, 495498.

[12] W. W. Schoeller, W. Haug, J. Strutwolf, T. Busch, J. Chem. Soc. Faraday Trans. 1996, 92, 17511755.

[13] S. Ito, M. Kikuchi, M. Yoshifuji, A. J. Arduengo, I. I. I. Tatyana, A. Konovalova, L. D. Kispert, Angew. Chem. 2006, 118, 4447 4451; Angew. Chem. Int. Ed. 2006, 45, 43414345.

[14] E. Niecke, A. Fuchs, F. Baumeister, M. Nieger, W. W. Schoeller, Angew. Chem. 1995, 107, 640 642; Angew. Chem. Int. Ed. Engl. 1995, 34, 555557.

[15] Y. Canac, A. Baceiredo, W. W. Schöller, D. Gigmes, G. Bertrand, J. Am. Chem. Soc. 1997, 119, 75797580.

[16] M. Soleilhavoup, Y. Canac, A. M. Polozov, A. Baceiredo, G. Bertrand, J. Am. Chem. Soc. 1994, 116, 61496152.

[17] For ab initio calculations on $\left[\mathrm{P}\left(\mathrm{PH}_{2}\right)_{2}\right]^{+}$, see: W. W. Schöller, T. Busch, Chem.Ber. 1990, 123, 971973.

[18] P. Jutzi, U. Meyer, Phosphorus Sulfur 1988, 40, 275277.

[19] a) R. Kroos, PhD thesis, Universität Bielefeld, 1989; b) P. Jutzi, R. Kroos, J. Organomet. Chem. 1990, 390, 317322.

[20] M. Scheer, E. Leiner, P. Kramkowski, M. Schiffer, G. Baum, Chem. Eur. J. 1998, 4, 19171923.

[21] M. Scheer, D. Himmel, Ch. Kuntz, S. Zhan, E. Leiner, Chem. Eur. J. 2008, 14, 90209029. 
[22] M. Schiffer, M. Scheer, Chem. Eur. J. 2001, 7, 1855 1861; M. Schiffer, M. Scheer, J. Chem. Soc. Dalton Trans. 2000, 2493 2494; for reviews, see: B. P. Johnson, G. Balázs, M. Scheer, Coord. Chem. Rev. 2006, 250, 1178 1195; G. Balázs, L. Gregoriades, M. Scheer, Organometallics 2007, 26, 30583075.

[23] M. Scheer, D. Himmel, B. P. Johnson, C. Kuntz, M. Schiffer Angew. Chem. 2007, 119, 4045 4049; Angew. Chem. Int. Ed. 2007, 46, 39713975.

[24] M. Schiffer, E. Leiner, M. Scheer, Eur. J. Inorg. Chem. 2001, 16611663

[25] See the Supporting Information.

[26] N. G. Connelly, W. E. Geiger, Chem. Rev. 1996, 96, 877910.

[27] The crystal structure analyses were performed on an OXFORD Diffraction Gemini R Ultra CCD diffractometer for $\mathbf{2}$ and 2. $\mathrm{CH}_{2} \mathrm{Cl}_{2}$ with $\mathrm{Mo}_{\mathrm{Ka}}$ radiation $(\lambda \quad 0.71073 \AA$ ) and for 3 and $5 \cdot 2.5 \mathrm{CH}_{2} \mathrm{Cl}_{2}$ with $\mathrm{Cu}_{\mathrm{Ka}}$ radiation $(\lambda \quad 1.54180 \AA)$. The structures were solved by direct methods with the program SHELXS $97,^{[30 \mathrm{a}]}$ and full matrix least square refinement on $F^{2}$ in SHELXL $97^{[30 b]}$ was performed with anisotropic displacements for non $\mathrm{H}$ atoms. Hydrogen atoms were located in idealized positions and refined isotropically according to the riding model. 2: $\mathrm{C}_{45} \mathrm{H}_{58} \mathrm{O}_{9} \mathrm{P}_{3} \mathrm{~W}_{2}, M_{\mathrm{r}} 1203.50$, crystal dimensions: $0.26 \times 0.22 \times$ $0.13 \mathrm{~mm}$, monoclinic, space group $C 2 / c, a$ 15.233(1), $b$ 20.720(1), c 15.969 (1) $\AA, \beta \quad 95.350(11)^{\circ}, T \quad 123(1) \mathrm{K}, Z$ 4, V $5018.2(7) \AA^{3}, \rho_{\text {calcd }} 1.593 \mathrm{~g} \mathrm{~cm}^{-3}, \mu \quad 4.725 \mathrm{~mm}^{-1}, 27710$ reflections collected, 5404 unique reflections $\left(R_{\text {int }} 0.0272\right.$, $\left.2 \Theta_{\max } \quad 53.80^{\circ}\right), 269$ parameters, $R_{1} \quad 0.0225, w R_{2} \quad 0.0579$; for 2. $\mathrm{CH}_{2} \mathrm{Cl}_{2}: \mathrm{C}_{46} \mathrm{H}_{60} \mathrm{O}_{9} \mathrm{Cl}_{2} \mathrm{P}_{3} \mathrm{~W}_{2}, M_{\mathrm{r}} \quad 1288.43$, crystal dimensions:
$0.45 \times 0.07 \times 0.03 \mathrm{~mm}$, monoclinic, space group $P 2_{1} / c, a$ 16.9423(9), b 11.1893(3), c 28.2800(15) $\AA$, $\beta \quad 105.750(5)^{\circ}$, $T \quad 150(1) \mathrm{K}, Z \quad 4, V \quad 5159.8(4) \AA^{3}, \rho_{\text {calcd }} 1.659 \mathrm{~g} \mathrm{~cm}^{-3}, \mu$ $4.701 \mathrm{~mm}^{-1}, 28905$ reflections collected, 7804 unique reflections

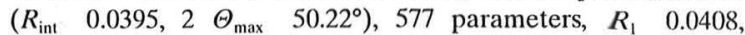
$w R_{2} \quad 0.0875 ; 3: \mathrm{C}_{45} \mathrm{H}_{59} \mathrm{O}_{9} \mathrm{P}_{3} \mathrm{~W}_{2}, M_{\mathrm{r}} 1204.52$, crystal dimen sions: $0.129 \times 0.076 \times 0.042 \mathrm{~mm}$, triclinic, space group $P 1, a$ 9.765(5), $\quad b \quad 10.916(5), \quad c \quad 24.443(5) \AA, \quad \alpha \quad 80.883(5), \quad \beta$ $80.772(5), \quad \gamma \quad 77.931(5)^{\circ}, \quad T \quad 150(1) \mathrm{K}, \quad Z \quad 2, \quad V$ 2493.8(18) $\AA^{3} . \rho_{\text {calcd }} 1.604 \mathrm{~g} \mathrm{~cm}^{-3}, \mu \quad 9.709 \mathrm{~mm}^{-1}, 49135 \mathrm{reflec}$ tions collected, 5352 unique reflections $\left(\begin{array}{ll}R_{\text {int }} & 0.0492,2 \Theta\end{array}\right.$ $\left.102.48^{\circ}\right), \quad 553$ parameters, $R_{1} \quad 0.0329, \quad w R_{2} \quad 0.0846$; $5 \cdot 2.5 \mathrm{CH}_{2} \mathrm{Cl}_{2}: \mathrm{C}_{57.5} \mathrm{H}_{73} \mathrm{O}_{9} \mathrm{P}_{3} \mathrm{~W}_{2} \mathrm{CoCl}_{5}, M_{\mathrm{r}} \quad 1604.95$, crystal dimen sions: $0.35 \times 0.06 \times 0.03 \mathrm{~mm}$, tetragonal, space group $P 4_{2} / n, a$ 30.031(1), $b \quad 30.031(1), c \quad 14.586(1) \AA, \alpha \quad \beta \quad \gamma \quad 90^{\circ}, T$ $123(1) \mathrm{K}, Z \quad 8, V \quad 13155.1(2) \AA^{3}, \rho_{\text {calcd }} 1.621 \mathrm{~g} \mathrm{~cm}^{-3}, \mu$ $11.238 \mathrm{~mm}^{-1}, 28824$ reflections collected, 9891 unique reflec tions $\left(R_{\text {int }} 0.0388,2 \Theta_{\max } 124.20^{\circ}\right), 723$ parameters, $R_{\mathrm{t}}$ $0.0498, w R_{2}$ 0.1113. CCDC 711409 (2) $711410 \quad\left(2 \cdot \mathrm{CH}_{2} \mathrm{Cl}_{2}\right)$ 711411 (3) and $711412\left(\mathbf{5} \cdot 2.5 \mathrm{CH}_{2} \mathrm{Cl}_{2}\right)$ contains the supplemen tary crystallographic data for this paper. These data can be obtained free of charge from The Cambridge Crystallographic Data Centre via www.ccdc.cam.ac.uk/data request/cif.

[28] A. Simon, H. Borrmann, J. Horakh, Chem. Ber: 1997, 130, 1235 1240 .

[29] L. Weber, Chem. Rev. 1992, 92, 18391906.

[30] a) G. M. Sheldrick, SHELXS 97, University of Göttingen, 1997; b) G. M. Sheldrick, SHELXL 97, University of Göttingen, 1997. 